\title{
Editorial: The Future of Psychology as an Open Access Journal Welcoming Applied Neuroscience
}

\author{
Peter Walla \\ Editorial des Chief Editors, School of Psychology, University of Newcastle, Callaghan, NSW, Australia \\ Email: peter.walla@newcastle.edu.au
}

Received 6 May 2014; revised 1 June 2014; accepted 28 June 2014

Copyright (c) 2014 by author and Scientific Research Publishing Inc. This work is licensed under the Creative Commons Attribution International License (CC BY). http://creativecommons.org/licenses/by/4.0/ (c)

In my role as editor in chief I want to take the chance to say a few words on behalf of the entire SCIRP team. The current times and trends within the world of academia are exciting. During the last few years various publishers followed the Open Access model, which I myself have found a great step forward since day one of its existence. Science is largely paid through money from the public and thus the public should have free access to its outcome. That is the fairest approach to it. Also, for a scientist it is much easier to distribute own work by simply sending a link that allows the recipient to freely download the respective article. In other words, Open Access is the future, which fortunately became the present already.

Our Open Access journal Psychology is life and online since 2010, enormously successful and has meanwhile been indexed in PsycINFO among of course various others. After only a few years it became a well known and well recognised platform to publish research outcome on highest quality levels and best standards. This success in only a short period of time has only been possible due to an extremely ambitious and capable team, the SCIRP team. However, we can only function with help from highly committed editorial board members and finally of course also help from all appreciated active reviewers. At this point I particularly want to thank all editorial board members and all reviewers without whom our journal could not survive.

Psychology covers a wide range of psychological topics, which I plan to even further expand to applied fields such as consumer psychology including consumer behaviour and also consumer neuroscience. Neuroscience within Psychology plays an increasingly important role and thus Psychology as a well established Open Access journal strongly welcomes any neuroscience contributions, especially the ones with an applied character. Psychology will become a major research outcome resource for not only scientists themselves, but also for marketers, advertisers and entire industries.

I am extremely happy about the development of our journal and invite all colleagues to publish their work with us. There is no better journal to publish your psychological research with than Psychology. Not just the most adequate journal title you can ever imagine, but more importantly the rigorous review standards together with a highly qualified team made it what it is. Share your research with the community via Psychology. 